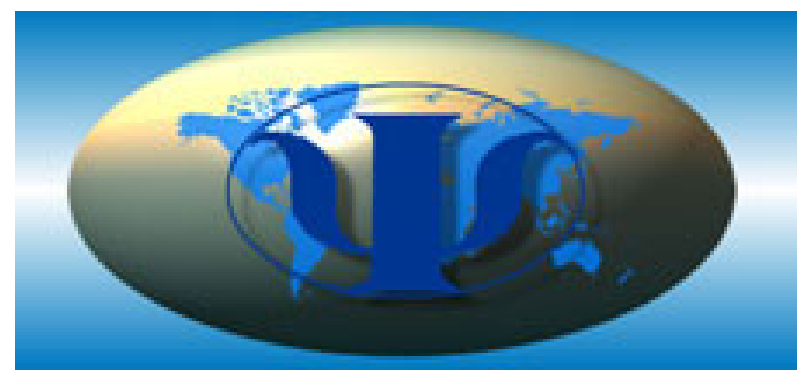

Personality and Politics: Values, Traits, and Political Choice

Author(s): Gian Vittorio Caprara, Shalom Schwartz, Cristina Capanna, Michele Vecchione, Claudio Barbaranelli

Source: Political Psychology, Vol. 27, No. 1 (Feb., 2006), pp. 1-28

Published by: International Society of Political Psychology

Stable URL: http://www.jstor.org/stable/3792381

Accessed: 17/01/2011 11:54

Your use of the JSTOR archive indicates your acceptance of JSTOR's Terms and Conditions of Use, available at http://www.jstor.org/page/info/about/policies/terms.jsp. JSTOR's Terms and Conditions of Use provides, in part, that unless you have obtained prior permission, you may not download an entire issue of a journal or multiple copies of articles, and you may use content in the JSTOR archive only for your personal, non-commercial use.

Please contact the publisher regarding any further use of this work. Publisher contact information may be obtained at http://www.jstor.org/action/showPublisher?publisherCode=ispp.

Each copy of any part of a JSTOR transmission must contain the same copyright notice that appears on the screen or printed page of such transmission.

JSTOR is a not-for-profit service that helps scholars, researchers, and students discover, use, and build upon a wide range of content in a trusted digital archive. We use information technology and tools to increase productivity and facilitate new forms of scholarship. For more information about JSTOR, please contact support@ jstor.org. 


\title{
Personality and Politics: Values, Traits, and Political Choice
}

\author{
Gian Vittorio Caprara
}

University of Rome "La Sapienza"

\section{Shalom Schwartz}

The Hebrew University of Jerusalem

\section{Cristina Capanna}

University of Rome "La Sapienza"

Michele Vecchione

University of Rome "La Sapienza"

Claudio Barbaranelli

University of Rome "La Sapienza"

\begin{abstract}
Voters' political choices have presumably come to depend more on their personal preferences and less on their social characteristics in Western democracies. We examine two aspects of personality that may influence political choice, traits and personal values, using the Five Factor Model of personality traits and the Schwartz (1992) theory of basic personal values. Data from 3044 voters for the major coalitions in the Italian national election of 2001 showed that supporters of the two coalitions differed in traits and values, largely as hypothesized. Center-left voters were higher than center-right voters in the traits of friendliness and openness and lower in energy and conscientiousness. Regarding values, center-left voters were higher than center-right voters in universalism, benevolence, and self-direction and lower in security, power, achievement, conformity, and tradition. Logistic regressions revealed that values explained substantial variance in past and future voting and in change of political choice, trumping personality traits. We discuss explanations for the primacy of values and implications for the social cognitive view of personality.
\end{abstract}

KEY WORDS: Personality, Values, Traits, Voting, Political Choice, Five Factor Model 
Politics in many democracies of the Western World has presumably become increasingly personalized (Caprara, Barbaranelli, \& Zimbardo, 1999, 2002; Giddens, 1998; Ricolfi, 2002). The personalization of politics encompasses two presumed processes. First, the personalities of candidates capture center stage and become the focus of voters' attention. Second, the individual personalities of voters, rather than their social locations in various interest groups, become decisive for political choice (Caprara \& Zimbardo, 2004). The current research examines the second presumed personalization process, which we call individualization. ${ }^{1}$

The importance of the personal characteristics of individuals for political choice may be increasing for several reasons (e.g., Wattenberg, 1998). The distinctiveness, diversity, and extremity of parties may be declining as they seek the political center to attract groups with diverse interests. Political issues are increasingly complex and political units increasingly interdependent, cutting across traditional cleavages. And the electorate is showing greater concern with social relations and intimacy. The current research studies the individualization of politics in Italy. We examine the role of individual personality traits and particularly of basic personal values in political choice.

Basic personal values refer to the broad goals to which people attribute importance as guiding principles in their lives (e.g., tradition, benevolence, hedonism). Basic values, as elaborated below, apply across domains and situations. As such, they underlie and are broader than the political values and attitudes typically examined in research on voter preferences. We see basic personal values as the crucial grounding of ideology. If they explain voting patterns, political leaders could use them to go beyond left-right and similar ideological dimensions to more complex readings of the range of the public's basic value priorities. They could segment the public based on fine-grained value priorities, not traditional group memberships. This would enable them better to communicate with the public, to assess the appeal of political positions, to frame political competition, and to organize and maintain cohesive political parties.

Early research on personality in politics dealt mainly with individual differences in the dispositions, attitudes, and motives of voters and leaders. Researchers proposed politically relevant constructs such as alienation (Seeman, 1959), conservatism (McClosky, 1958), dogmatism (Rokeach, 1960), and power (Browning \& Jacob, 1964; Winter, 1973). The absence of a general theory of personality functioning limited this research, however, as did the lack of agreed upon methods to assess personality. No integrated conceptual vision guided the early research, nor did it adequately attend to situational factors that might interact with personal dispositions (Greenstein, 1975). It was therefore difficult to compare findings and build cumulative knowledge (Brewer-Smith, 1968; Knutson, 1973). A broad

\footnotetext{
${ }^{1}$ Our ongoing studies examine the first process, the role of candidates' personalities and images in political choice.
} 
literature attests to the merits and limitations of these early approaches (e.g., Knutson, 1973; Simonton, 1990).

We conceive of personality as a set of dynamic, self-regulatory systems that emerge and operate over the life course in the service of personal adaptations (Caprara \& Cervone, 2000). These internal systems guide affective, cognitive, and motivational processes, directing people toward achieving individual and collective goals. They provide coherence and continuity in behavioral patterns across different settings, and they create, foster, and preserve a sense of personal identity (Bandura, 2001; Caprara \& Cervone, 2000; Mischel \& Shoda, 1998).

\section{Traits and Personal Values}

The current research investigates relations of two aspects of personality to political choice - traits and personal values. Traits and values are rooted in different intellectual traditions, the former in personality psychology, and the latter in social psychology. Traits and values tell us different things about personality functioning. Each may be particularly relevant to different aspects of the political process.

Traits are "dimensions of individual differences in tendencies to show consistent patterns of thought, feelings, and actions" (McCrae \& Costa, 1990, p. 23). Values are cognitive representations of desirable, abstract, trans-situational goals that serve as guiding principles in people's life (Schwartz, 1992). Consider additional differences between traits and personal values (Bilsky \& Schwartz, 1994; Roccas, Sagiv, Schwartz, \& Knafo, 2002). Traits are enduring dispositions, whereas values are enduring goals. Traits describe what people are like; values refer to what people consider important. Traits vary in the frequency and intensity of their occurrence; values vary in their priority as standards for judging behavior, events, and people. People believe their values are desirable to their significant reference others, whereas traits may be positive or negative. People may explain behavior by referring to traits or to values, but they refer to values when they wish to justify choices or actions as legitimate or worthy.

Several mechanisms link traits and values (Roccas et al., 2002). Inborn temperaments (e.g., high need for arousal) may give rise to parallel traits (e.g., excitement seeking) and values (stimulation). Values and traits may influence one another reciprocally. ${ }^{2}$ Values may affect traits because, other things equal, people try to behave consistently with their values (Rokeach, 1973; Schwartz, 1996). Values serve as ideals or oughts and hence as guides for self-regulation. People may change their behavior in order to reduce discrepancies they sense between their values and behavior (Carver \& Scheier, 1981). Traits may affect values because people who consistently exhibit a behavioral trait are likely to increase

${ }^{2}$ This contrasts with the view of McCrae and Costa (1999) that traits are the genotype of personality that is not influenced by constructs like values (cf. Bardi \& Schwartz, 2003). 
the degree to which they value the goals that trait serves. This permits them to justify the behavior (Kristiansen \& Zanna, 1994; Schwartz \& Bardi, 1997). Selfperception theory (Bem, 1972) might suggest that traits influence values because people infer what is important to them from their consistent (trait-expressive) behavior.

Given the differences between traits and personal values and the links between them, one would expect them to exhibit moderate empirical correlations. Roccas et al. (2002) report just such correlations (ranging from .16 to .48) between traits in the Five Factor Model (McCrae \& John, 1992) and the conceptually related values in the Schwartz (1992) theory of values. Roccas et al. (2002) also demonstrate the functional distinctiveness of traits and values. They postulate that traits and values are important for predicting different kinds of behavior. Their theorizing is central to our expectations for the relative importance of traits and values in predicting political choice. We elaborate on it below.

\section{The Current Research}

This study assesses the relative contribution of traits and personal values to political choice, controlling for some basic demographic variables typically used as predictors in most research by political scientists. A study of the Italian elections of 1994 demonstrated significant associations between voters' own traits and their political preferences (Caprara et al., 1999). A study of the 1988 Israeli elections demonstrated that individuals' personal values discriminated significantly between voters for the various political parties (Barnea \& Schwartz, 1998; Barnea, 2003, details similar findings in 13 other countries). This report is the first to compare the importance of these two aspects of personality for political choice. It is a first step toward disentangling the personality-politics associations that are better understood with a traits analysis from those that are better understood with a values analysis.

Roccas et al. (2002) theorized that the relative strength of traits and values as predictors of a behavior or attitude depends upon the degree to which that behavior or attitude is spontaneous or is under voluntary, intentional control. Traits are likely to trump values as predictors of spontaneous, habitual, automatic responses over which individuals exert little cognitive control, such as positive affect. In support of this view, traits predicted approximately five times as much variance in positive affect as values did in their study.

As habitual patterns of perceiving reality and behaving, traits are likely to be brought "online" more spontaneously, set off almost automatically by the context. Trait inferences and attributions may be activated automatically when forming impressions of the personality of politicians. They may therefore be more important than values as determinants of liking for politicians. A match between voters' own personality and the personality they attribute to a candidate would create or strengthen the bond between the voter and candidate. The policy positions of a 
party may also reverberate with particular individual traits. Emphases on using force to quash terror or on free enterprise to overcome poverty, for example, may reverberate with persons high on the dominance trait. Thus, voters' own personality characteristics may make particular candidates or parties appear more appealing to them.

Roccas et al. (2002) further theorized that values are likely to trump traits as predictors of responses when the degree of voluntary, intentional control over a decision or judgment is high. In support of this view, values predicted approximately five times as much variance in religiosity as traits did. This is because values represent motivations cognitively in the form of desirable goals and objectives that people can pursue intentionally. The trade-off among competing values that are implicated simultaneously in a behavior or attitude gives direction to that behavior or attitude (Schwartz, 1996, 2005a). Personal values should predict people's voting choices more powerfully than traits do, because such choices are intentional and typically entail thoughtful processing. People weigh alternatives and their implications in light of the personal standards that guide their behavior.

Complex, thoughtful processing of values might be expected to characterize voters who are more rather than less cognitively sophisticated. If we take education level as a proxy for cognitive sophistication, values might relate more strongly to political choice among university-educated voters. We examine this possibility.

An abundant literature reports relations of specific values that are relevant in the political domain to political attitudes and choice (e.g., Feldman, 1988; Knutsen, 1995; Miller \& Shanks, 1996; Rokeach, 1973; Zaller, 1992). This literature has not considered even more basic values that may provide the grounding in personality for such political values as humanitarianism, materialism, and traditionalism. Schwartz (1994) argues that combinations of basic values underlie specific political values and ideologies. The latter may mediate the effects of basic values on political choice but basic values are more fundamental. Basic personal values may enable people to organize their political evaluations in a relatively consistent manner; they can provide a general structure to political attitudes (Feldman, 2003). This structuring process is another path through which basic values may influence voting. Converse likened values to "a sort of glue to bind together many more specific attitudes and beliefs" (1964, p. 211).

The particular values that structure ideological discourse depend upon the issues that are central in a given political context. In the Israeli political arena of 1988 , for example, where protection of religious practice competed with free expression of a secular lifestyle, the key values that differentiated party supporters were tradition versus self-direction (Barnea \& Schwartz, 1998). In her study of 14 countries, Barnea (2003) found that, where political competition revolved around issues of national security versus equal rights and freedoms for all, the key values whose relative priorities structured voters' preferences tended to be security and conformity versus universalism and self-direction. Where the focus of political 
competition revolved around the distribution of material resources, the key values tended to be universalism and benevolence versus power and achievement.

In sum, while we expect traits to predict voting, our overarching hypothesis is that personal values have primacy over traits. This hypothesis comports with a view of personality as a proactive self-regulating, agentic system operating in the pursuit of own goals (Bandura, 1997, 2000; Caprara \& Cervone, 2000). After analyzing the political context in Italy at the time of this study, we specify the particular traits and values hypothesized to predict voting.

The causal order linking values to behavior is a key issue in values research (e.g., Kristiansen \& Zanna, 1994). In the domain of voting, McCann (1997) found that the effect of vote preferences on core political values in the American presidential election of 1992 was greater than the reciprocal effect of these values on vote preferences. He theorized that, as individuals come to back a candidate during an election campaign, their values change to become more compatible with those of the chosen candidate and party. We agree that basic values do change over time, though slowly (Rokeach, 1973; Schwartz, 2005b), and that values and voting may have reciprocal influences. Nonetheless, we doubt the relevance of McCann's analysis to the current study for two reasons.

First, McCann studied core political values that concern what is good or bad for the society or country. We refer to basic personal values that apply in all domains of individual life. These basic values may underlie core political values, but the full range of people's experiences in all life domains affects them. Hence, their vulnerability to the impact of the events in the one, limited, life domain of politics should be substantially lower. Second, the American and Italian electoral contexts differ in a critical way. Political debate that draws public interest peaks once in four years during presidential campaigns in America. Otherwise, it is low. Hence, during these campaigns, political mobilization may induce change in core political values. In Italy (and much of Europe), local, regional, and national elections are more frequent and irregular. Political tension is chronically high and political mobilization is largely continuous because governments may fall at any time (Caciagli \& Corbetta, 2002; Sani, 1979). Hence, mobilization during any particular campaign is less likely to affect core political values, let alone basic personal values.

Personality Traits. To study traits, we adopted the Five Factor Model (FFM) of personality. The FFM provides a consensual, objective, quantifiable description of the main surface tendencies of personality (Caprara, Barbaranelli, \& Livi, 1994). The five factors have various names: emotional stability or neuroticism, extraversion or energy, agreeableness or friendliness, ${ }^{3}$ conscientiousness, and openness to experience or intellect/culture. Advocates of the FFM claim that it provides a comprehensive and reasonably adequate summary of major individual differences (Digman, 1990; McCrae \& John, 1992; Wiggins, 1996).

\footnotetext{
${ }^{3}$ We use the labels "energy" and "friendliness," the constructs in our measurement instrument.
} 
Table 1. Definitions of Ten Value Constructs and Sample PVQ Items

Value and Motivational Goal

Power: social status and prestige, control or dominance over people and resources.

Achievement: personal success through demonstrating competence according to social standards.

Hedonism: pleasure and sensuous gratification for oneself.

Stimulation: excitement, novelty, and challenge in life.

Self-direction: independent thought and action-choosing, creating, exploring.

Universalism: understanding, appreciation, tolerance, and protection for the welfare of all people and for nature.

Benevolence: preservation and enhancement of the welfare of people with whom one is in frequent personal contact.

Tradition: respect, commitment, and acceptance of the customs and ideas that traditional culture or religion provide the self.

Conformity: restraint of actions, inclinations, and impulses likely to upset or harm others and violate social expectations or norms.

Security: safety, harmony, and stability of society, of relationships, and of self.
Sample Items ${ }^{\mathrm{A}}$

"He likes to be in charge and tell others what to do. He wants people to do what he says."

"Being very successful is important to him. He likes to stand out and to impress other people."

"He really wants to enjoy life. Having a good time is very important to him."

"He looks for adventures and likes to take risks. He wants to have an exciting life."

"He thinks it's important to be interested in things. He is curious and tries to understand everything."

"He wants everyone to be treated justly, even people he doesn't know. It is important to him to protect the weak in society."

"He always wants to help the people who are close to him. It's very important to him to care for the people he knows and likes."

"He thinks it is important to do things the way he learned from his family. He wants to follow their customs and traditions."

"He believes that people should do what they're told. He thinks people should follow rules at all times, even when no-one is watching."

"It is important to him to live in secure surroundings. He avoids anything that might endanger his safety."

${ }^{\mathrm{A}}$ The PVQ forms were gender appropriate, varying only in the pronouns.

Basic Values. To study relations of values to political preferences, we adopted the Schwartz (1992) theory of basic personal values. This theory derived 10 basic values from universal requirements of the human condition: power, achievement, hedonism, stimulation, self-direction, universalism, benevolence, tradition, conformity, and security. Each value expresses a distinct motivational goal. Table 1 presents the definitions of each of the 10 values in terms of its central goal, that is, the end state to which it is directed.

The theory specifies the structure of dynamic relations among the values. Openness to change values (self-direction, stimulation) encourages independence of thought, feeling, and action, and receptiveness to change. They conflict with conservation values (conformity, tradition, security) that call for submissive self-restriction, preserving traditional practices, and protecting stability. Selftranscendence values (universalism, benevolence) emphasize accepting others as equals and concern for their welfare. They conflict with self-enhancement values 


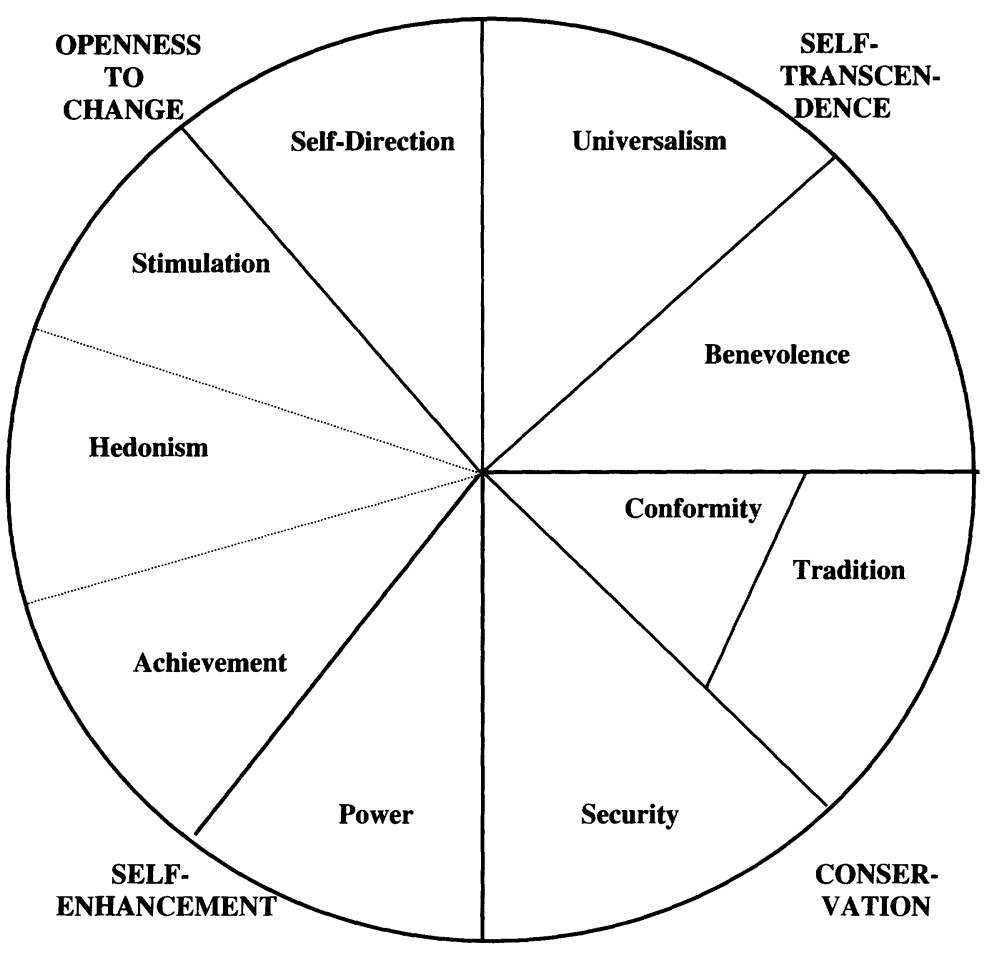

Figure 1. The motivational continuum of 10 values.

(power, achievement) that encourage pursuing one's own relative success and dominance over others. Hedonism values share elements of both openness and self-enhancement.

The 10 values form a motivational continuum based on their pattern of compatibility and conflict. Figure 1 depicts this continuum in the form of a motivational circle. The order of the values in Table 1 follows this circle. Tests of the theory in more than 200 samples from 67 countries largely support both the content of the 10 values and the structure of relations among them (Schwartz, 1992, 1994, 2005a).

Value priorities have been used as predictors of voting behavior in 14 democratic countries chosen to represent culturally distinct world regions (Barnea, 2003; Barnea \& Schwartz, 1998). In every country, value priorities discriminated significantly among supporters of the different political parties. The specific values that predicted voting varied across countries. Which values were crucial depended on the nature of the political conflict or discourse in each nation. Every one of the 10 values was a significant discriminator in several countries at least. People tended to vote for parties whose platform or image suggested that 
electing them would promote attainment or preservation of their own cherished, personal values. They did not vote for parties whose election they perceived as threatening these values. For example, voters who gave high priority to selfdirection and universalism but low priority to power and security tended to vote for parties that emphasized individual freedom and programs to help the poor but not for parties that were more concerned with nationalism and maintaining law and order.

Below, we generate hypotheses about relations of specific values and traits to political preferences. For this purpose, it is necessary to analyze what the political choices in the specific sociopolitical context imply for the particular values and traits. We therefore briefly present the case of politics in Italy, the setting in which we conducted this research.

\section{The "Italian Case"}

Since the early 1990s, Italy has undergone a remarkable political transition. Political parties traditionally at opposite poles of a right-left political continuum have regressed toward the center. New coalitions have formed, meshing prior political antagonists into pragmatically organized entities, under new banners, broadly appealing slogans, and contingently varying policies. Formerly, the conservative-right and the liberal-left differed on many sociological variables. For example, women, older people, those with higher incomes, and more professional or white-collar occupations, tended to vote for the center or the right. The new Italian coalitions cut across such traditional boundaries (Caciagli \& Corbetta, 2002).

The established order of Christian Democrats, Socialists, and Communists collapsed in the 1990s after 40 years. Two main coalitions replaced them, centerleft and center-right. Some former Christian Democrats, ex-Socialists, exRepublicans, and all the ex-Communists joined the center-left. The remaining Christian Democrats, Socialists, ex-Liberals, heirs of the neo-Fascists, and a separatist movement from Northern Italy migrated to the center-right. The centerright coalition captured the 1994 election, but lost to the center-left in 1996. The center-left ruled the country until the next elections in 2001, when the center-right returned to power.

As in many other European countries, right and left in Italy have lost most of their traditional ethos. Both coalitions champion the principles of liberal democracy. However, the center-right emphasizes entrepreneurship and the market economy as a means to generate wealth and provide people with the resources to protect their security. It also emphasizes security, limited government, and family and national values. In contrast, the center-left continues to advocate the merits of the welfare state, expresses strong concern for social justice, and emphasizes pluralism and equality (Bobbio, 1994; Caciagli \& Corbetta, 2002; Veneziani, 1994). 


\section{Hypotheses}

As noted, specific personality profiles on the Big Five correlated significantly with preferences for the two political coalitions in a study of over 2000 Italian voters in 1994 (Caprara et al., 1999). Controlling for demographic characteristics, personality profiles of voters mirrored, to a considerable extent, the primary aims and images conveyed by the two leading coalitions and their leaders. The centerright campaigned mostly on entrepreneurship and business freedom. Consistent with this platform, respondents identified its leader's image with energy. The center-left campaigned mostly on solidarity, social welfare, education, and tolerance for diversity. Respondents identified its leader's image more with friendliness and openness. Correspondingly, the self-reported personalities of center-left voters were higher in friendliness and openness than those of center-right voters; the latter's personalities were higher in energy (and conscientiousness).

Thus, voters' personalities tend to be congruent both with the personality profile their coalition's leader projects and with the political priorities of the coalition. This congruence may be due to actual correspondence between voters' political preferences and their self-reported personality and/or to voters assimilating their preferred candidates' personalities to their own. In either case, two mechanisms might account for the link of traits to voting. First, the similarityattraction paradigm suggests that voters feel more attracted to a leader or coalition whose personality and policies they perceive as more congruent with their own personality. This attraction, in turn, inclines them to vote for the leader or coalition. Second, voting serves an expressive function for voters. By voting for a coalition whose programs they perceive as congruent with their own actual or ideal traits, voters actively express and affirm that they themselves possess the traits they wish or believe they have. Leaders reinforce the link between voters' personalities and their political choices by projecting the traits that voters value.

The images and policies of the two coalitions and leaders in the 2001 elections were similar to those in 1994. Therefore, in keeping with past findings, we hypothesized that center-right supporters in the 2001 elections would be higher than center-left supporters in energy and conscientiousness and that center-left supporters would be higher in friendliness and openness. The effect-sizes for personality traits in the 1994 elections were quite small (Caprara et al., 1999), perhaps because the two coalitions were not strongly distinguished on most issues. Because this situation persisted in 2001, we anticipated that associations with voting would be weak.

To generate hypotheses for personal values we assessed the implications of the policy differences between the coalitions for value attainment. As noted, the center-right placed particular emphasis on entrepreneurship and the market economy, security, and family and national values. The expected consequences of such a policy are compatible with power, security, and achievement values. But they may harm the opposing values in the value circle, universalism and, perhaps, 
benevolence. The latter values call for promoting the welfare of others even at cost to the self. In addition, universalism values express concern for the weak, those most likely to suffer from market-driven policies.

In contrast, the center-left advocated social welfare, concern for social justice, equality, and tolerance of diverse groups, even those that might disturb the conventional social order. The expected consequences of such a policy are particularly compatible with universalism values and with benevolence values. On the other hand, they conflict with pursuing individual power and achievement values and with security values that emphasize preserving the social order.

Thus, political choice in these elections consisted of a trade-off between power, security, and achievement values on the right and universalism and benevolence values on the left. On that basis, we hypothesized that voters supporting the center-left versus center-right correlate most positively with the priority given to universalism values and most negatively with the priority given to power values. Correlations with the priority of benevolence values should also be positive, and those with security and achievement values negative. Because the 10 values form a motivational circle, we can formulate this as a single integrated hypothesis: Correlations should decline from most positive for universalism values to most negative for power values in both directions around the circle (see Figure 1).

Finally, as hypothesized above, we expected values to take primacy over traits in predicting voting. Voting is a choice under intentional control that typically entails conscious consideration among alternatives. Two central characteristics of values are relevant to this hypothesis. First, values serve as standards to evaluate people and events, to define what individuals prefer. They may provide an underlying structure for people's vague political orientations. With the individualization of politics, individuals' value-based judgments of policies and candidates may govern voting preferences to a considerable extent. Second, values serve to direct attention and perception, to influence what we notice and how we interpret it. During elections, when citizens seek information about politicians and policies, their values influence which information they attend to and how they evaluate that information.

\section{Method}

\section{Participants}

A sample of 4,376 individuals completed a set of questionnaires that measured traits, values, and voting in the Italian national election of 2001 . We excluded from the analyses 490 respondents who had voted for parties other than the two main coalitions. We also excluded 291 respondents who had not voted and 551 who failed to report their vote. The remaining 3,044 participants included in the analyses split nearly evenly between voters for the center-right (43.6\%) and the centerleft $(56.4 \%)$. 
Psychology students in introductory statistics courses at the University of Rome "La Sapienza" collected the data. Each student was requested to collect data from six people, equally distributed by gender and age. Students were briefed on the general aims of the research and instructed how to administer the instruments. Data were collected during three periods, nine months after the 2001 election ( $n=573$ included in the analyses), 18 months $(n=915)$, and 27 months $(n=$ 1,556). This convenience sample showed substantial variance on key demographic characteristics: Age $\mathrm{M}=43.4(s=16.2)$; $46.6 \%$ male, $53.4 \%$ female; annual income mode $=23,750$ Euro, $\mathrm{M}=34,829(s=28.693) ; 6.9 \%$ elementary school education, $12.9 \%$ junior high school, $55.6 \%$ high school, $24.6 \%$ college.

\section{Measures}

Traits. We measured the trait component of personality with a short version of the Big Five Questionnaire (BFQ) (Caprara, Barbaranelli, Borgogni, \& Perugini, 1993; Caprara et al., 1994). The short form of the BFQ used here contains 60 items that form five domain scales and 10 "facet" scales, with six items on each scale. Table 2 presents a short definition of the domain scales and facets and one sample item for each facet. Respondents indicate agreement with the extent to which each item describes them on a 5-point scale ranging from complete disagreement ( $1=$ very false for me) to complete agreement $(5=$ very true for me).

The original extended form of the BFQ (132 items) was validated on large samples of Italian respondents (Barbaranelli \& Caprara, 2000; Caprara et al., 1993, 1994) and in cross-cultural comparisons (Caprara, Barbaranelli, Bermudez, Maslach, \& Ruch, 2000). High correlations between the analogous scales in the BFQ and the NEO-PI, in both Italian and American samples, confirmed the construct validity of the five domain scales (Barbaranelli, Caprara, \& Maslach, 1997; Caprara et al., 1993).

The short form included the items with the best psychometric properties from the BFQ. The alpha reliability coefficients of the five domain scales ranged from .70 (energy) to .85 (emotional stability), and of the 10 facet scales from .53 (cooperativeness) to .81 (emotion control). The short form yielded a pattern of factor loadings and intercorrelations fully consistent with the 132-item BFQ, indicating good measurement of traits with the short form.

Values. We measured values with the Portrait Values Questionnaire (PVQ: Schwartz, 2005b; Schwartz, Melech, Lehmann, Burgess, \& Harris, 2001). The PVQ includes 40 short verbal portraits of different people, each describing a person's goals, aspirations, or wishes that point implicitly to the importance of a value. For example, "It is important to him to listen to people who are different from him. Even when he disagrees with them, he still wants to understand them" describes a person who holds universalism values important. The PVQ measures each of the 10 motivationally distinct types of values with from three to six items. For each portrait, respondents indicate how similar the person is to themselves 
Table 2. Definitions of Global Trait Domains, Trait Facets, and Sample BFQ Items

\begin{tabular}{|c|c|}
\hline Global Domains & Facets and Sample Items \\
\hline $\begin{array}{l}\text { Energy: Level of activity, vigor, } \\
\text { sociability, talkativeness, need } \\
\text { to excel, persuasiveness, } \\
\text { competitiveness }\end{array}$ & $\begin{array}{l}\text { Dynamism: Activity and enthusiasm ("I am an active and } \\
\text { vigorous person"). } \\
\text { Dominance: Assertiveness and self-confidence ("Generally } \\
\text { I tend to assert myself rather than give in"). }\end{array}$ \\
\hline $\begin{array}{l}\text { Friendliness: Concern and } \\
\text { sensitiveness towards } \\
\text { others and their needs }\end{array}$ & $\begin{array}{l}\text { Cooperativeness: Altruism, empathy, generosity, } \\
\text { unselfishness ("I understand when people need my } \\
\text { help"). } \\
\text { Politeness: Kindness, civility, docility, and trust (“Usually } \\
\text { I'm cordial even to people I dislike"). }\end{array}$ \\
\hline $\begin{array}{l}\text { Conscientiousness: Self-regulation } \\
\text { in both its proactive and } \\
\text { inhibitory aspects }\end{array}$ & $\begin{array}{l}\text { Scrupulousness: Dependability, orderliness, and precision } \\
\text { ("Before completing a job I spend a lot of time } \\
\text { revising it"). } \\
\text { Perseverance: Capability of fulfilling one's own tasks and } \\
\text { commitments, tenaciousness, persistence ("I always } \\
\text { pursue the decisions I've made through to the end"). }\end{array}$ \\
\hline $\begin{array}{l}\text { Emotional Stability: Capability } \\
\text { to control one's emotional } \\
\text { reactions, absence of negative } \\
\text { affects, psychological } \\
\text { adjustment }\end{array}$ & $\begin{array}{l}\text { Emotion Control: Absence of anxiety, depression, and } \\
\text { vulnerability, mood stability ("I often feel nervous"). } \\
\text { Impulse Control: Capability of controlling irritation, } \\
\text { discontent, and anger ("I'm rather touchy"). }\end{array}$ \\
\hline $\begin{array}{l}\text { Openness: Broadness of one's } \\
\text { own cultural interests, tolerance } \\
\text { of diversity, exploration of novelty }\end{array}$ & $\begin{array}{l}\text { Openness to Culture: Intellectual curiosity, interest in } \\
\text { being informed, appreciation of culture ("I'm always } \\
\text { informed about what's happening in the world"). } \\
\text { Openness to Experiences: Openness to novelty, tolerance } \\
\text { of values, interest toward diverse people, habits, and } \\
\text { life-styles ("I'm fascinated by novelties"). }\end{array}$ \\
\hline
\end{tabular}

on a scale ranging from "very much like me" to "not like me at all." We infer respondents' own values from the implicit values of the people they consider similar to themselves.

Studies in seven countries supported the reliability of the PVQ for measuring the 10 values (Schwartz, 2005b). Multimethod-multitrait analyses in Germany, Israel, and Ukraine compared measurement of the 10 values using the PVQ and with an earlier instrument that was validated across 70 countries. These analyses confirmed the convergent and discriminant validity of the 10 values measured by the PVQ. In the current study, the alpha reliability coefficients ranged from .61 (tradition) to .83 (achievement). Some of the values have conceptually broad definitions, encompassing multiple components (e.g., tradition includes both selfrestriction and faith). Measurement of these values with only three to six items may account for their relatively low internal consistency. The PVQ indexes have demonstrated predictive validity for numerous behaviors and attitudes (Schwartz, 2005b; Schwartz et al., 2001).

Voting. We measured political choice directly by asking participants which coalition they had voted for in the September 2001 election. In the second and 
third data-gathering rounds, respondents also indicated the coalition they would vote for in the next, future election. We coded vote as (0) for center-right and (1) for center-left.

Stability of Traits and Values. Our theorizing spelled out how individual differences in traits and values might influence voting. However, we measured traits and values subsequent to voting. Only if individual differences in these personality variables exhibit substantial temporal stability, can we posit that these differences were largely present prior to the vote. In an Italian convenience sample, correlation across time for the 10 trait facets of the BFQ over a two-year interval, during which a national election took place, ranged from .77 to $.96(\mathrm{M}=.87$; $\mathrm{n}=207$ ), corrected for attenuation. In a representative French national sample, correlation across time for the 10 values of the PVQ over a two-year interval, during which a national election also took place, were .75 to $.94(\mathrm{M}=.85$; $\mathrm{n}=870$ ), corrected for attenuation. These levels of temporal stability are compatible with the possibility that the traits and values measured here reflected traits and values that existed prior to voting in 2001 and may have influenced it.

To assess actual prediction, if only of future vote, we replicated the analyses with this indicator of political choice. We also assessed whether values related more strongly to political choice among more sophisticated voters. For this purpose, we predicted 2001 vote separately in the subsamples of universityeducated vs. less-educated respondents.

\section{Statistical Analyses}

We calculated point-biserial correlations, controlling demographic variables, between voting and each of the $10 \mathrm{BFQ}$ facets and $10 \mathrm{PVQ}$ values to test the hypothesized relations. We used the $10 \mathrm{BFQ}$ facets or subdimensions rather than the five domain scales to have an equal number of values and personality traits for comparing their predictive power. We examined the impact of traits and values on political choice with hierarchical logistic regression. In the regression, we first controlled age, gender, income, and education. We constructed three dummy variables for education-elementary school, junior high school, and university (senior high school omitted as the reference group). We then examined whether the set of traits and/or the set of personal values explained significant additional variance $^{4}$ in voting and whether any one set of variables took primacy over the others.

To avoid capitalizing on chance, we adjusted the alpha level for individual tests in the logistic regressions downwards, according to the number of predictors

\footnotetext{
${ }^{4}$ The goodness-of-fit index in the logistic regression is the Nagelkerke $\mathrm{R}^{2}$. It "is scaled in the same manner as $\mathbf{R}^{2}$ from OLS regression [range 0 to 1], but the two are not directly the same" (Cohen, Cohen, West, \& Aiken, 2003, p. 503). Nagelkerke $\mathrm{R}^{2}$ is useful to evaluate competing models, but is not, strictly speaking, a measure of variance explained (Hosmer \& Lemeshow, 2000). Keeping this in mind, we use the expression "variance explained."
} 
included in equation ( $\mathrm{p}<.01$ at first block, $\mathrm{p}<.001$ at second and third block), using the Bonferroni method. To be conservative in light of sample size, we set an alpha level of .001 to test increments in $\chi^{2}$.

\section{Results}

\section{Correlations of Traits and Values with Political Choice}

We hypothesized that voters higher in friendliness and openness and lower in energy and conscientiousness would support the center-left as compared with the center-right coalition. This hypothesis assumed that voters perceived the leader of the center-left coalition as higher in friendliness and openness and as lower in energy and conscientiousness than the leader of the center-right coalition. At the second data-gathering period, respondents rated the personalities of the coalition leaders on a list of adjectives that serve as markers of the Big Five traits. The expected differences in perceptions were all confirmed (all $p<.001){ }^{5}$

We computed point-biserial correlations of voting with the 5 traits and 10 facets, controlling gender, age, income, and education. In the combined sample from the three periods $(\mathrm{n}=2,849)$, the correlation with friendliness $(.15, p<.001)$ supported the hypothesis, as did the correlations with its two facets, cooperativeness $(.14, p<.001)$ and politeness $(.11, p<.001)$. The correlation with openness $(.11, p<.001)$ also supported the hypothesis, as did the correlations with its facets, openness to culture $(.08, p<.001)$ and openness to experience $(.09, p<.001)$. The correlation with energy $(-.07, p<.001)$ also supported the hypothesis, but this reflected only its dominance facet $(-.10, p<.001)$ and not its dynamism facet $(-.01)$. The correlations with conscientiousness $(.06, p<.01)$ and its facets (scrupulousness $.05, p<.01$, persistence $.04, p<.05$ ) were also in the hypothesized direction. Voting did not correlate with emotional stability (.01) or with its facets of emotion control (.00) and impulse control (.02). The correlations of voting with each of the five traits and their facets were similar at each of the three data-gathering periods.

With regard to values, we hypothesized that voters who value universalism and benevolence more and power, security, and achievement less would support the center-left as compared with the center-right coalition. More specifically, we expected voting to correlate most positively with universalism values and most negatively with power values. Moreover, based on the motivational continuum that organizes values, we predicted an integrated pattern of relations between voting preferences and the whole set of value priorities. We expected correlations to decline from most positive for universalism values to most negative for power values in both directions around the motivational circle of values (Figure 1).

\footnotetext{
${ }^{5}$ Data are available from the authors.
} 
Table 3. Correlations with Vote for Center-Left of Ten Basic Personal Values Measured at Three Times, Controlled for Age, Gender, Income, and Education

\begin{tabular}{lcccc}
\hline Value & $\begin{array}{c}9 \text { Months } \\
\text { Post Election } \\
\mathrm{N}=529\end{array}$ & $\begin{array}{c}19 \text { Months } \\
\text { Post Election } \\
\mathrm{N}=881\end{array}$ & $\begin{array}{c}27 \text { Months } \\
\text { Post Election } \\
\mathrm{N}=1,439\end{array}$ & $\begin{array}{c}\text { Total } \\
\text { Sample } \\
\mathrm{N}=2,849\end{array}$ \\
\hline Power & -.11 & $-.16^{* *}$ & $-.14^{* *}$ & $-.14^{* *}$ \\
Achievement & -.08 & $-.16^{* *}$ & -.05 & $-.08^{* *}$ \\
Hedonism & -.06 & .01 & -.01 & -.01 \\
Stimulation & -.07 & .03 & .05 & .03 \\
Self-Direction & .04 & .01 & $.11^{* *}$ & $.08^{* *}$ \\
Universalism & $.26^{* *}$ & $.30^{* *}$ & $.28^{* *}$ & $.28^{* *}$ \\
Benevolence & $.18^{* *}$ & $.21^{* *}$ & $.16^{* *}$ & $.18^{* *}$ \\
Tradition & -.01 & .01 & $-.12^{* *}$ & $-.07^{* *}$ \\
Conformity & -.08 & $-.10^{*}$ & $-.11^{* *}$ & $-.10^{* *}$ \\
Security & $-.14^{* *}$ & $-.22^{* *}$ & $-.22^{* *}$ & $-.20^{* *}$ \\
\hline
\end{tabular}

${ }^{* *} p<.001,{ }^{*} p<.01$, two-tailed.

We computed point-biserial correlations of voting with the 10 values, controlling gender, age, income, and education. We centered individuals' value responses on their own mean for all 40 items to eliminate individual differences in use of the response scale. In the combined sample, as hypothesized, the pointbiserial correlation of universalism with voting for the center-left rather than center-right $(.28, p<.001)$ was the most positive, and the correlation for benevolence $(.18, p<.001)$ was positive too. The hypothesized negative correlations were also significant-security -.20 , power -.14 , and achievement -.08 (all $p<$ .001 ) - though it was security rather than power that correlated most negatively. Table 3 presents the correlations of voting with the 10 values separately for each data-gathering period. The pattern of correlations is largely similar at the three post-election intervals.

The hypothesized pattern of relations between voting preferences and the whole set of value priorities was also confirmed. The Spearman rank correlation between the expected and observed order of correlations around the value circle, starting at universalism, is 1.00 for the total sample and $.95, .94$, and .96 for the 9-, $19-$, and 27-month periods, respectively (all $p<.001$ ). Figure 2 portrays the pattern of correlations for the total sample. It reveals the sinusoidal shape expected based on the motivational continuum of values (Schwartz, 1992).

\section{Logistic Regression}

The logistic regression coefficients we report are odds ratios $(O R)$. They indicate the effect of a one-unit change in a predictor variable on the odds that a person preferred the center-left coalition (coded 1), holding all other predictors constant. Thus, coefficients greater than 1 indicate that the higher people's score 


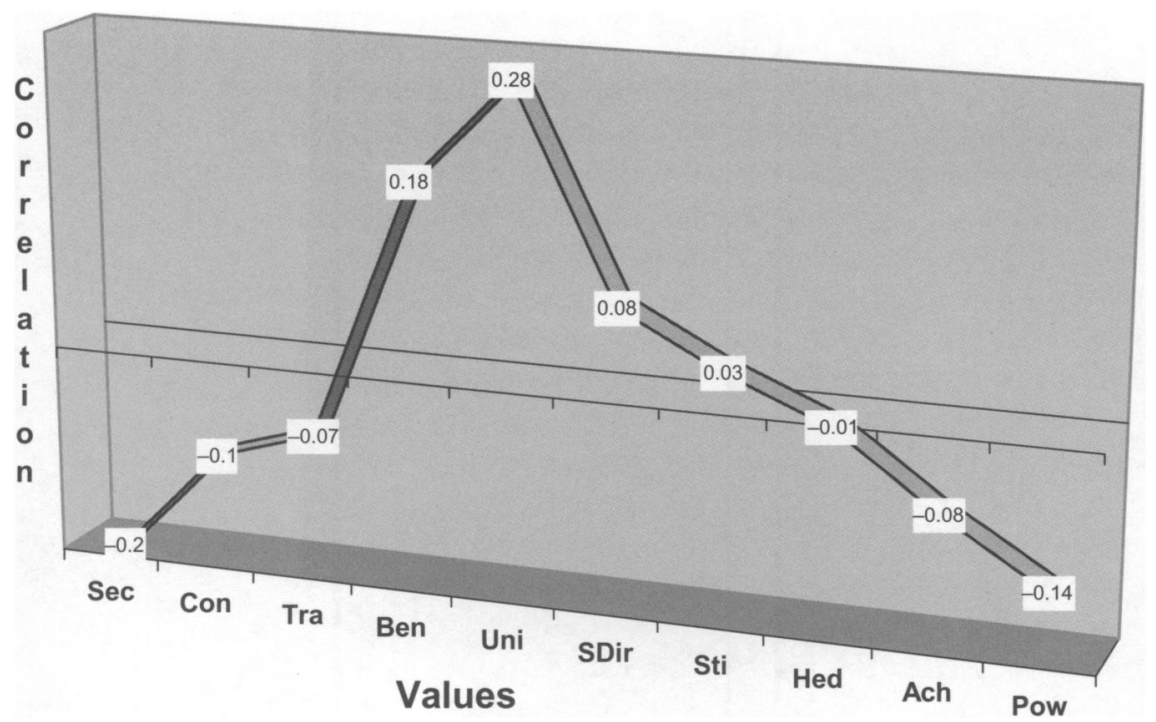

Figure 2. The pattern of correlations between voting preferences and the 10 values, total sample.

on the independent variable the greater the odds that they are center-left voters. Coefficients smaller than 1 indicate that the higher the score on the independent variable the greater the odds that they are center-right voters.

Table 4 summarizes the results for the total sample. Model 1 entered the demographic variables (gender, age, income, and three dummy variables for education) as a first block of predictors, followed by the 10 trait facets as a second block, and the 10 values as a third block. Model 2 entered the values following the demographic variables and then the trait facets.

Model 1. Inclusion of the demographic variables significantly improved the model that includes only the intercept $\left(\Delta \chi^{2}(6 d f)=44.19, p<.001\right)$. Gender and education, entered as a first block, had significant $(p<.001)$ impacts on political preference (Panel 1 of Table 4). Females $(O R=1.327)$ and university graduates $(O R=1.544)$ voted more for the center-left coalition.

Adding all 10 personality trait facets in the second block further improved prediction $\left(\Delta \chi^{2}(10 d f)=138.63, p<.001\right)$. Five traits contributed significantly $(p<.001)$ : Cooperativeness $(O R=1.558)$, openness to experience $(O R=1.289)$, and openness to culture $(O R=1.276)$ predicted a center-left orientation; dominance $(O R=.743)$ and scrupulousness $(O R=.792)$ predicted a center-right orientation. Traits and demographics together allowed the correct classification of $42.6 \%$ of center-right voters and $76.8 \%$ of center-left voters, with an overall "hit" rate of $61.9 \%$. Traits alone accounted for $6.5 \%$ of the variance in political orientation. Traits and demographic variables together explained $8.7 \%$ of the variance in voting. 


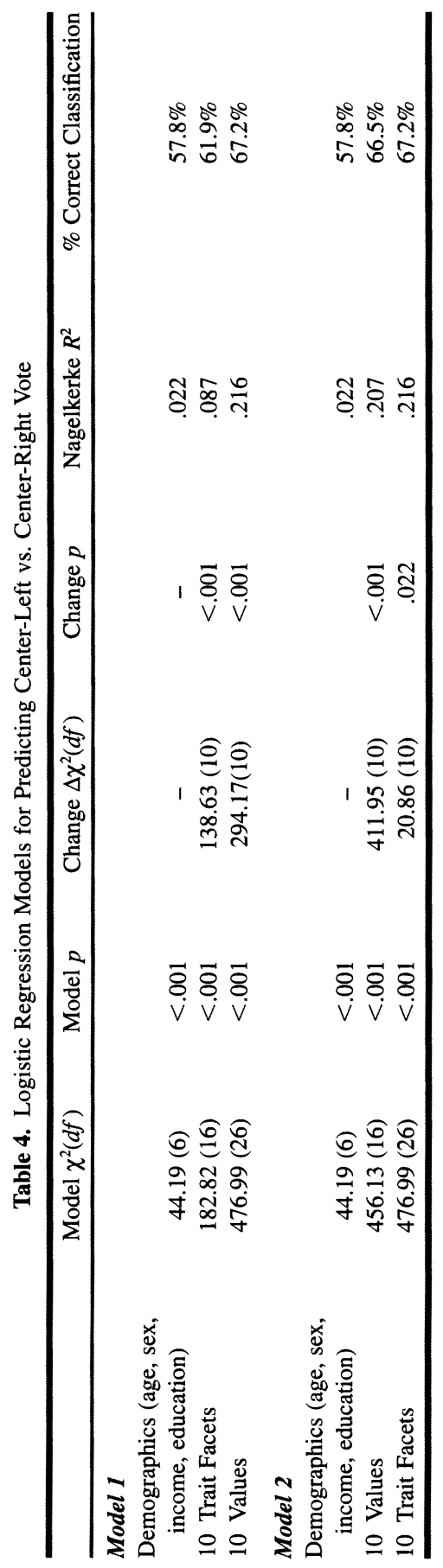


Addition of values as a third block further improved prediction $\left(\Delta \chi^{2}(10 d f)=\right.$ $294.17, p<.001)$. Four values contributed significantly $(p<.001)$ : Universalism $(O R=2.384)$ predicted a preference for the center-left, whereas security $(O R=$ $.557)$, tradition $(O R=.748)$, and conformity $(O R=.749)$ predicted a preference for the center-right. The other values that correlated significantly with voting did not contribute significantly in the regression because of their interdependence with the other predictors.

The equation including demographic variables, trait facets, and values allowed the correct classification of $56.1 \%$ of center-right voters and $75.8 \%$ of center-left voters, with an overall "hit" rate of $67.2 \%$. It explained $21.6 \%$ of the variance in voting.

Model 2. Again, we entered demographics as a first block. Adding the 10 values in a second block improved prediction $\left(\Delta \chi^{2}(10 d f)=411.95, p<.001\right)$. Five values contributed significantly $(p<.001)$ : Universalism $(O R=2.492)$ predicted a center-left orientation, whereas security $(O R=.541)$, conformity $(O R$ $=.750)$, tradition $(O R=759)$, and power $(O R=.836)$ predicted a center-right orientation. Values alone accounted for a substantial $16.8 \%$ of the variance in political choice. Adding all 10 traits in the third block did not improve prediction significantly $\left(\Delta \chi^{2}(10 d f)=20.86, p=.02\right)$. None of the 10 trait facets contributed significantly to predicting political choice, once values were in the model. Power values also dropped out.

As noted, a model including demographics, traits, and values yielded a correct classification of $67.2 \%$ of voters. This was significantly better than chance $(z H=$ $16.31, \mathrm{p}<.001$; see Huberty, 1984). Separate logistic regressions for the samples from each data-gathering period all yielded similar results. ${ }^{6}$ In each case, when we entered values into the regression before traits, the latter made no significant additional contribution to the variance explained.

Future Vote. We also performed the above analyses on respondents' reports of their anticipated future vote. All correlations of traits and of values with future vote were very similar to those with 2001 vote computed for the same respondents $(N=2,356)$. The same correlations were statistically significant and no correlation differed by more than .02 from the equivalent correlation with the 2001 vote. The Spearman rank correlation between the expected and observed order of correlations around the value circle, starting at universalism, was 1.00 .

In the logistic regression for future vote $(N=1,892)$, the demographic variables contributed significantly $(p<.001)$ but accounted only for minimal variance $(1.8 \%)$. Both traits and values explained significant additional variance $(p<.001)$. The 10 traits alone accounted for $9.2 \%$ of the variance in future vote when entered following the demographic variables and for $1.6 \%$ when entered following values. The 10 values alone accounted for $24.1 \%$ of the variance in future vote when entered following the demographic variables and for $16.5 \%$ when entered follow-

\footnotetext{
${ }^{6}$ Analyses available from the authors.
} 
ing traits. Thus, this analysis reconfirms the primacy of personal values over both traits and a limited set of demographic variables in predicting political choice. Four values predicted future vote for the center-left versus the center-right coalition $(p<.001)$ : universalism $(O R=3.10)$, security $(O R=.49)$, tradition $(O R=$ $.69)$, and conformity $(O R=.71)$. Only the trait facet of dynamism predicted significantly $(O R=.77, p<.01)$.

As a stringent test of the predictive power of values and traits, we examined whether they could account for change in coalition choice from the 2001 election to future vote (only $3.5 \%$ of respondents reported such change). For this purpose, we repeated the logistic regression, first entering 2001 vote as a predictor of future vote. Neither the demographic variables $\left(\Delta \chi^{2}(6 d f)=8.20, p=.22\right)$ nor the traits $\left(\Delta \chi^{2}(10 d f)=8.20, p<.61\right)$ accounted for any of the change in coalition choice. In contrast, values did $\left(\Delta \chi^{2}(10 d f)=34.81, p<.001\right)$. Priority for universalism values predicted the shift from center-right to center-left $(O R=$ $2.53, p<.001)$, and priority for security values predicted the opposite shift (OR $=.50, p<.002$ ).

Sophistication of Voters. In the introduction, we raised the possibility that thoughtful processing of values might characterize voters who are more sophisticated. Hence, values might predict voting more strongly among more sophisticated voters. We used university education as the best available proxy for sophistication, splitting the sample on this variable. We regressed voting on age, gender, income, and values, setting an alpha level of .001 for entry in a stepwise procedure. In the university-educated sample $(N=740)$, only values accounted for significant variance in voting. In the less-educated sample $(N=2,130)$, both age and gender predicted voting in addition to values. The variance in age and gender did not differ across the two samples. The total variance in political choice accounted for by values alone was greater in the university sample than in the less-educated sample (.204 versus .165). These findings provide some support for the idea that voter sophistication may increase the impact of values on voting.

\section{Discussion}

This study yields substantial evidence for the impact of personality on vote choice. Five of the 10 trait facets correlated significantly $(p<.001)$ with voting, all in the hypothesized direction. We had expected voters high in self-reported friendliness and openness and low in energy and conscientiousness to prefer the center-left to the center-right coalition. The correlations reveal that both facets of friendliness (cooperativeness and politeness) and both facets of openness (openness to culture and openness to experience) functioned as expected. For, energy, only the dominance, and not the dynamism facet, related to a preference for the center-left. Correlations with voting of conscientiousness and both its facets (scrupulousness and perseverance) indicated only a weak preference for the center-right. 
These results suggest that the emphasis of the center-left programs on solidarity and collective well-being and on education and tolerance for diversity made it more attractive to "friendly" and "open" people. Moreover, such people could better express and affirm their own personalities by voting for the center-left. The emphasis of the center-right programs on individual entrepreneurship and business freedom probably made that coalition more attractive for "energetic, dominant" people and made voting for it more self-expressive. The dominance but not the dynamism facet of energy was associated with voting for the center-right, replicating a finding from the 1994 elections (Caprara et al., 1999). What characterizes center-right voters is not their level of enthusiasm or activity, but their sense of dominant self-confidence and assertiveness. Berlusconi, leader of the center-right coalition, also projected dominance and assertiveness in his speeches and campaign propaganda.

We based the hypotheses of relations between values and political preferences on the implications for value attainment of policy differences between the coalitions. The center-left coalition advocated social welfare, concern for social justice, equality, pluralism, and tolerance of diverse groups, even those that might disturb the conventional social order. Such a policy is most expressive of universalism values (emphasizing understanding, appreciation, tolerance, and protection for the welfare of all people) and also of benevolence values. This policy sharply opposes the self-enhancing goals of power and achievement values (status, dominance, personal success) and threatens the goal of preserving the social order central to security values. In contrast, the center-right coalition advocated the virtues of the market economy as a way to generate wealth and reward individual initiative and emphasized family and national security. This policy is congruent with the goals of power and security and achievement values.

The correlations of values with voting fully supported the analysis based on the value implications of coalition policies. Additional significant, weaker, correlations of values also supported this analysis. Tradition and conformity values that, like security values, endorse the status quo, correlated with voting for the centerright. Self-direction values, that share the tolerance for diversity with universalism values, correlated with voting for the center-left.

Based on the dynamic structure of conflict and congruence among the 10 values, we hypothesized that the correlations with center-left versus center-right voting would decline from most positive for universalism values to most negative for power values around the motivational circle. As illustrated in Figure 2, the results supported this hypothesis, though security rather than power values were most negative. The analyses for each subsample and for future vote also supported the order of correlations based on the circular structure of values. These systematic relations of personal values to voting mirror the motivational continuum that underlies value priorities. This finding shows that voters for one coalition versus the other differ in their whole system of value priorities, not only in the importance they give to a few values. The observed pattern of correlations identifies the critical 
value trade-off underlying voting in these elections as the trade-off between values concerned with preserving the status quo and self-enhancement versus those concerned with tolerance and other-enhancement. Security values were the strongest predictor of voting for the right-center coalition. This suggests that the emphasis of this coalition on family and national security values may have been more critical in drawing voters to it than its emphasis on entrepreneurship.

The logistic regression (model 1) revealed that the personality traits added significantly to the prediction of voting by demographic variables. The $61.9 \%$ correct classification of voters using traits and demographics is about the same as in the 1994 elections (59.4\%). Hence, the test of whether values take primacy over traits in the current study started with a level of prediction that gave traits a "fair" chance. The logistic regression (model 2) revealed that basic personal values added substantially to the prediction of voting by demographic variables, accounting for an additional $18.5 \%$ of the variance. The final step of model 2 asked whether traits add predictive power to values. The nonsignificant change in $\chi^{2}$ revealed that traits did not account for additional variance. Not only did values take primacy, they fully trumped traits.

The logistic regressions for predicting future vote yielded similar results. Even more impressive were the results of predicting change between 2001 vote and intended future vote. Neither demographic variables nor traits accounted for any of this change. However, the priority attributed to universalism and security values did. In sum, the logistic regressions confirm the critical hypothesis of this research: Values take primacy over traits in predicting voting.

One mechanism through which values might affect political choice is by guiding people as they weigh the implications of choice alternatives for attaining or damaging their important values. Such thoughtful use of values may be more common among sophisticated voters. Two findings lend some support for this mechanism. Values accounted for more variance in voting among university graduates than among less-educated respondents; values alone predicted voting among the former, whereas age and gender also predicted among the latter.

This same mechanism suggests that values might relate more strongly to political choice among first time than among veteran voters. Novice voters would not yet have developed habitual voting behavior and might therefore assess the alternatives more thoughtfully. Because of the small number of novice voters in our sample, we could not evaluate this possibility reliably. Future studies should address it. Bardi and Schwartz (2003) have argued and shown, however, that values also predict habitual behavior for which current processing

\footnotetext{
${ }^{7}$ This was not due to multicollinearity. Correlations between trait facets and values, controlling demographic variables, were all less than .56 . Moreover, no trait facet that predicted significantly before values were added to the regression correlated more than .39 with any value that predicted significantly when added. Nor did any regression coefficient change appreciably in magnitude or sign when values were added to traits in the model or vice versa.
} 
is low. They postulate that values affect initial choices, which may then become routine. If so, values may predict voting nearly as well among veteran as among novice voters. ${ }^{8}$

Compared with basic personal values, four characteristics that locate voters in groups that may differ in their interests-income, education, age, and gender-differentiated very little among supporters of the two coalitions. ${ }^{9}$ Did we overlook social cleavages in Italy that might account for political choice? In the United States, race and religion constitute other politically relevant cleavages (Miller \& Shanks, 1996). The Italian population in 2000, however, was overwhelmingly of a single ethnic group (96\% Italian) and religion (82\% identified Catholic and 13\% nonreligious Catholics), and 99\% were native-born (Encyclopedia Britannica Almanac, 2003). The weakness of group membership as a predictor of voting in this election may not generalize to elections in other countries. Group membership may be more important in contexts where sharply differentiated party platforms link more obviously with group-based interests and where loyalty to established parties is transmitted across generations.

Note three other limits to the generalizability of the findings. The central issues in the political discourse of an election probably determine the specific values that are relevant. Consider an election whose central issue is protecting civil liberties versus controlling crime and threats to personal security. In this context, the critical value trade-off may be self-direction and stimulation versus security/conformity/tradition. To clarify the interactions between personality and social context in determining political choice, future research should study elections that vary systematically in their core issues. Employing the comprehensive set of 10 broad values used here can enrich such research. These values can encompass the various specific and contingent goals that may matter in political choices.

Second, although our theorizing suggests that values ordinarily predict voter choice better than traits do, the specific electoral context may influence their relative importance. Giving more prominence to candidates' personalities in a campaign and less to party platforms would make personal liking of candidates more salient. This might increase the importance of voters' traits. Greater clarity of issues and differentiation of party policies, on the other hand, might make the implications of choice for value attainment more salient and increase the

\footnotetext{
${ }^{8}$ On theoretical and conceptual grounds, we have argued that a causal link from basic values to voting makes more sense in the current context than the reverse order. If the main causal process ran from electoral choice to values (cf. McCann, 1997), we might expect stronger relations between values and voting the shorter the interval between the election and the measurement of values. However, there was no decrease in the strength of relations as the post-election interval increased across the three data-gathering periods. This is not a definitive empirical test of causality, of course. It is desirable to evaluate the causal relations between basic values and voting directly in future research.

${ }^{9}$ Perhaps, group membership mattered more for the $14 \%$ of voters we excluded because they chose a minor coalition.
} 
importance of personal values. This deserves study. Third, $86 \%$ of voters chose between two coalitions in the Italian elections. In elections with three or more serious contenders, political choice may be more complex. Complexity might sharpen the issues, increasing the importance of values. Conversely, it might confuse the electorate, reducing value importance.

\section{Conclusions}

Past studies identified the pivotal role that personality traits may play in understanding political choices. The present research goes a step further and shows that values subsume traits in predicting political orientation. The primacy of values over traits accords well with the view of personality as a proactive, agentic system, in which personal goals and standards usually drive voluntary behavior (Bandura, 2001; Caprara \& Cervone, 2000). The findings further attest to the reflexiveness and purposiveness of individuals whose habits and choices often match the implicit principles that guide their lives. Personality encompasses multiple levels and constructs that come together in the functioning of the person as a coherent and unique system.

McAdams (1996) suggested that a complete analysis of personality functioning would include three levels: a trait level with decontextualized constructs like the Big Five; a level of contextualized goals, expectations, and skills; and a narrative level of stories people construct to attain and maintain a stable and coherent sense of identity. Social cognitive theory distinguished other constructs to account for the coherence and direction of conduct: dispositions, mastery beliefs, competences, goals, and personal standards (Caprara, 2002; Caprara \& Cervone, 2000; Mischel \& Shoda, 1999). Both these approaches identify what we conceptualize as a trait aspect (dispositions) and a values aspect (goals, standards) of personality.

Other authors have pointed to the importance of personal values in political choice and have assigned a pivotal role to value-like concepts (e.g., Himmelweit, Humphreys, Jaeger, \& Katz, 1981; Rokeach, 1973). For example, Mitchell, Tetlock, Mellers, and Ordonez (1993) investigated the role of values in guiding political choices in a hypothetical society. They inferred that "disagreements between liberals and conservatives are rooted not just in different assumptions about how to promote economic growth or in different conceptions of their self-interest but in fundamental values" (p. 637).

We view basic personal values of the type studied here as expressions of personal ideologies that organize core political orientations (Feldman, 2003; Schwartz, 1994). When politicians emphasize their commitment to "social justice" (universalism) or to "family values" (tradition and security), they are appealing to the basic values that shape individuals' attitudes toward specific ideological issues. Parties seeking broad support often clothe their aims in language that hides contradictory value claims. They profess to favor a free market (power and 
achievement) and social welfare (universalism; e.g., Italy's Alleanza Nazionale), or promise to battle terrorism (security and power) and protect freedom (selfdirection). Knowledge of the congruencies and conflicts inherent in the circular motivational structure of the 10 basic values can help analysts and politicians alike to identify contradictory or coherent ideological stands.

Both traits and values have long been considered relevant to political choice, but little attention has been paid to how they operate in concert. The current research built upon taxonomies of traits and values with welldocumented cultural generality and usefulness across domains of action. Our findings corroborate a social cognitive view that assigns primacy to values over traits in the course of actions and choices that entail thoughtful weighing of alternatives, currently or in the past. Personal values can serve to operationalize the personal standards and goals that the social cognitive view sees as critical guides to behavior. Placing values within the social cognitive theoretical framework that specifies their role in the functioning of human agency gives values broader heuristic value. The primacy of values over traits in the current context is noteworthy both for research on political reasoning and choice and for research on personality functioning.

Sociologists note a general individualizing of society in the democracies of the Western World (e.g., Bellah, Madsen, Sullivan, Swidler, \& Tipton, 1985; Ester, Halman, \& de Moor, 1994). They argue that higher education and greater geographical and occupational mobility have weakened people's bonds to their traditional social groups and to the ideologies and parties these groups endorse. Education and mobility encourage people to formulate more autonomous social and political views rather than to adopt packaged views from groups to which they feel little allegiance. Presumably, voluntary lifestyle groups (sports, music, travel) are increasingly important. They are less linked to ascribed groups and their interests and more expressive of personal values and preferences. People's distinctive attitudes towards self and life serve more as the compass that orients their behavior. Our evidence that basic personal values and traits have greater relevance than demographic group memberships in orienting political choice in Italy adds to this picture of individualization.

\section{ACKNOWLEDGMENTS}

We thank Moshe Berger, Ariel Knafo, Yuval Piurko, and Tammy Rubel for comments on an earlier version of this paper. The work of the second author on this research was supported by Israel Science Foundation Grant No. 921/02-1. Correspondence concerning this article should be addressed to Gian Vittorio Caprara (Department of Psychology, University of Rome "La Sapienza," Via dei Marsi 78, 00185 Rome, Italy). E-mail: gianvittorio.caprara@uniroma1.it or msshasch@ mscc.huji.ac.il 


\section{REFERENCES}

Bandura, A. (1997). Self-efficacy: The exercise of control. New York: Freeman.

Bandura, A. (2000). Social cognitive theory: An agentic perspective. Annual Review of Psychology, 52, $1-26$.

Bandura, A. (2001). Social cognitive theory: An agentic perspective. Annual Review of Psychology, 52, $1-26$.

Barbaranelli, C., \& Caprara, G. V. (2000). Measuring the Big Five in self-report and other ratings: A multitrait-multimethod study. European Journal of Psychological Assessment, 16, 31-43.

Barbaranelli, C., Caprara, G. V., \& Maslach, C. (1997). Individuation and the Five Factor model of personality traits. European Journal of Psychological Assessment, 13, 75-84.

Bardi, A., \& Schwartz, S. H. (2003). Values and behavior: Strength and structure of relations. Personality and Social Psychology Bulletin, 29, 1207-1220.

Barnea, M. (2003). Personal values and party orientations in different cultures. Unpublished doctoral dissertation, The Hebrew University of Jerusalem, Israel.

Barnea, M., \& Schwartz, S. H. (1998). Values and voting. Political Psychology, 19, 17-40.

Bellah, R. N., Madsen, R., Sullivan, W. M., Swidler, A., \& Tipton, S. M. (1985). Habits of the heart: Individualism and commitment in American life. Berkeley: University of California Press.

Bem, J. (1972). Self-perception theory. In L. Berkowitz (Ed.), Advances in experimental social psychology, 6, 1-62. New York: Academic Press.

Bilsky, W., \& Schwartz, S. H. (1994). Values and personality. European Journal of Personality, 8, 163-181.

Bobbio, N. (1994). Destra e Sinistra [Right and left]. Rome, Italy: Donzelli.

Brewer-Smith, M. (1968). A map for the analysis of personality and politics. Journal of Social Issues, $24,15-28$.

Browning, R., \& Jacob, H. (1964). Power motivation and the political personality. Public Opinion Quarterly, 28, 75-90.

Caciagli, M., \& Corbetta, P. (2002). Le ragioni dell'elettore. Perché ha vinto il centro-destra nelle elezioni italiane del 2001 [The voter's reasons. Why the center-right won the Italian elections in 2001]. Bologna, Italy: Il Mulino.

Caprara, G. V. (2002) Personality psychology: Filling the gap between basic processes and molar functioning. In C. von Hofsten \& L. Backman (Eds.), Psychology at the turn of the millennium, Vol. 2: Social, developmental and clinical perspectives (pp. 201-224). New York: Psychology Press, Taylor \& Francis Group.

Caprara, G. V., \& Cervone, D. (2000). Personality: Determinants, dynamics and potentials. Cambridge: Cambridge University Press.

Caprara, G. V., \& Zimbardo, P. (2004). Personalizing politics: A congruency model of political preference. American Psychologist, 59, 581-594.

Caprara, G. V., Barbaranelli, C., \& Livi, S. (1994). Mapping personality dimensions in the Big Five model. European Review of Applied Psychology, 44, 9-15.

Caprara, G. V., Barbaranelli, C., \& Zimbardo, P. (1999). Personality profiles and political parties. Political Psychology, 20, 175-197.

Caprara, G. V., Barbaranelli, C., \& Zimbardo, P. (2002). When parsimony subdues distinctiveness: Simplified public perceptions of politicians' personality. Political Psychology, 23, 77-96.

Caprara, G. V., Barbaranelli, C., Borgogni, L., \& Perugini, M. (1993). The Big Five questionnaire: A new questionnaire to assess the Five Factor Model. Personality and Individual Differences, 15, 281-288. 
Caprara, G. V., Barbaranelli, C., Bermudez, J., Maslach, C., \& Ruch, W. (2000). Multivariate methods for the comparison of factor structures in cross-cultural research: An illustration with the Big Five questionnaire. Journal of Cross Cultural Psychology, 31, 437-464.

Carver, C. S., \& Scheier, M. F. (1981). Attention and self-regulation: A control-theory approach to human behavior. New York: Springer-Verlag.

Cohen, J., Cohen, P., West, S. G., \& Aiken, L. S. (2003). Applied multiple regression/correlation analysis for the behavioral sciences. London: Erlbaum.

Converse, P. E. (1964). The nature of belief systems in mass publics. In D. E. Apter (Ed.), Ideology and discontent (pp. 206-261). New York: Free Press.

Digman, J. M. (1990). Personality structure: Emergence of the five factors model. Annual Review of Psychology, 41, 417-440.

Encyclopedia Britannica Almanac 2003 (2002). Chicago: Encyclopedia Brittanica, Inc.

Ester, P., Halman, L., \& de Moor, R. (1994). The individualizing society: Value change in Europe and North America. Tilburg, the Netherlands: Tilburg University Press.

Feldman, S. (1988). Structure and consistency in public opinion: The role of core beliefs and values. American Journal of Political Science, 32, 416-440.

Feldman, S. (2003). Values, ideology, and structure of political attitudes. In D. O. Sears, L. Huddy, \& R. Jervis (Eds.), Oxford handbook of political psychology (pp. 477-508). New York: Oxford University Press.

Giddens, A. (1998). The third way: The renewal of social democracy. Oxford: Polity.

Greenstein, F. I. (1975). Personality and politics. In F. I. Greenstein \& N. W. Polsby (Eds.), The handbook of political science (vol. 2, pp. 1-92). Reading, MA: Addison Wesley.

Himmelweit, H., Humphreys, P., Jaeger, M., \& Katz, M. (1981). How voters decide: A longitudinal study of political attitudes and voting extending over fifteen years. London: Academic Press.

Hosmer, D. W., \& Lemeshow, S. (2000). Applied Logistic Regression. New York: Wiley.

Huberty, C. J. (1984). Issues in the use and interpretation of discriminant analysis. Psychological Bulletin, 95, 156-171.

Knutsen, O. (1995). Party choice. In J. W. van Deth \& E. Scarbrough (Eds.), The impact of values (pp. 460-491). New York: Oxford University Press.

Knutson, J. (1973). Handbook of Political Psychology. San Francisco: Jossey-Bass.

Kristiansen, C. M., \& Zanna, M. P. (1994). The rhetorical use of values to justify social and intergroup attitudes. Journal of Social Issues, 30, 47-65.

McAdams, D. P. (1996). Alternative futures for the study of human individuality. Journal of Research in Personality, 30, 374-388.

McCann, J. A. (1997). Electoral choices and core values change: The 1992 presidential campaign. American Journal of Political Science, 41, 564-583.

McClosky, H. (1958). Conservatism and personality. American Political Science Review, 52, 2745.

McCrae, R. R., \& Costa, P. T. (1990). Personality in adulthood. New York: Guilford.

McCrae, R. R., \& Costa, P. T. (1999). A five-factor theory of personality. In L. A. Pervin \& O. P. John (Eds.), Handbook of personality: Theory and research (pp. 139-153). New York: Guilford Press.

McCrae, R. R., \& John, O. P. (1992). An introduction to the five-factor model and its applications. Journal of Personality, 60, 175-216.

Miller, W., \& Shanks, J. M. (1996). The new American voter. Cambridge: Harvard University Press.

Mischel, W., \& Shoda, Y. (1998). Reconciling processing dynamics and personality dispositions. Annual Review of Psychology, 49, 229-258.

Mischel, W., \& Shoda, Y. (1999). Integrating dispositions and processing dynamics within a unified theory of personality: The cognitive-affective personality system. In L. A. Pervin \& O. P. John 
(Eds.), Handbook of personality: Theory and research (2nd ed., pp. 197-218). New York: Guilford.

Mitchell, P. G., Tetlock, P. E., Mellers, B. A., \& Ordonez, L. (1993). Judgments of social justice: Compromises between equality and efficiency. Journal of Personality and Social Psychology, 65, 629-639.

Ricolfi, L. (2002). La frattura Etica. La ragionevole sconfitta della sinistra [The ethical rift. The reasonable defeat of the left]. Naples, Italy: L'Ancora del Mediterraneo.

Roccas, S., Sagiv, L., Schwartz, S. H., \& Knafo, A. (2002). The Big Five personality factors and personal values. Personality and Social Psychology Bulletin, 28, 789-201.

Rokeach, M. (1960). The open and closed mind: Investigations into the nature of belief systems and personality systems. New York: Basic Books.

Rokeach, M. (1973). The nature of human values. New York: Free Press.

Sani, G. (1979). Ricambio elettorale, mutamenti sociali e preferenze politiche [Electoral replacement, social changes, and political preferences]. In L. Graziono \& S. Tarrow (Eds.), La crisi Italiana. Torino, Italy: Einaudi.

Schwartz, S. H. (1992). Universals in the content and structure of values: Theoretical advances and empirical tests in 20 countries. In M. Zanna (Ed.), Advances in experimental social psychology, 25, 1-65. New York: Academic Press.

Schwartz, S. H. (1994). Are there universal aspects in the structure and contents of human values? Journal of Social Issues, 50, 19-45.

Schwartz, S. H. (1996). Value priorities and behavior: Applying a theory of integrated value systems. In C. Seligman, J. M. Olson, \& M. P. Zanna (Eds.), The psychology of values: The Ontario symposium (Vol. 8, pp. 1-24). Hillsdale, NJ: Erlbaum.

Schwartz, S. H. (2005a). Basic human values: Their content and structure across cultures. In A. Tamayo \& J. Porto (Eds.), Valores e trabalho [Values and work]. Brasilia: Editora Vozes.

Schwartz, S. H. (2005b). Robustness and fruitfulness of a theory of universals in individual human values. In A. Tamayo \& J. Porto (Eds.), Valores e trabalho [Values and work]. Brasilia: Editora Vozes.

Schwartz, S. H., \& Bardi, A. (1997). Influences of adaptation to communist rule on value priorities in Eastern Europe. Political Psychology, 18, 385-410.

Schwartz, S. H., Melech, G., Lehmann, A., Burgess, S., \& Harris, M. (2001). Extending the crosscultural validity of the theory of basic human values with a different method of measurement. Journal of Cross Cultural Psychology, 32, 519-542.

Seeman, M. (1959). On the meaning of alienation. American Sociological Review, 24, 783-791.

Simonton, D. K. (1990). Personality and politics. In L. Pervin (Ed.), Handbook of personality (pp. 670-692). New York: Guilford.

Veneziani, M. (1994). Sinistra e Destra [Left and right]. Florence, Italy: Vallecchi.

Wattenberg, M. P. (1998). The decline of American political parties. Cambridge: Harvard University Press.

Wiggins, J. S. (1996). An informal history of the interpersonal circumplex tradition. Journal of Personality Assessment, 66, 217-233.

Winter, D. G. (1973). The power motive. New York: Free Press.

Zaller, J. (1992). The nature and origins of mass opinion. New York: Cambridge University Press. 